\title{
Blephaochalasis Syndrome in A Patient With Polycystic Kidney Disease
}

\author{
Maria Cecilia Argibay ${ }^{1 *}$, Matias Agustin Intili ${ }^{2}$ \\ ${ }^{1}$ Department of Opthalmology, Chief of oculoplastic service, Santa Lucia Eye Private Clinic, Argentina \\ ${ }^{2}$ Department of Opthalmology, MD pgy3 ophthalmology, Argentina
}

*Corresponding author: Maria Cecilia Argibay, Department of Opthalmology, Chief of oculoplastic service, Santa Lucia Eye Private Clinic, Argentina.

Received Date: July 27, 2020

Published Date: August 27, 2020

\section{Introduction}

Polycystic kidney disease is caused by an inherited genetic defect. It develops into chronic kidney disease producing generalized edema.

Blepharochalasis syndrome is a rare disease with repeated episodes of eyelid edema followed by loss of subcutaneous tissue with consequent eyelid ptosis and weakening of the orbital septum. It must be differentiated from other pathologies that have some of its main characteristics such as edema, ptosis and recurrent inflam mation. The etiology is still unknown, being its incidence higher in young adults with no gender difference. Current medical and/or surgical treatments fail to guarantee long-term solutions or definitive resolution to disease-related relapses.

In most of the researched works, they opt for surgical resolution, despite the fact that in many cases patients usually have re currences, even reaching ptosis. Surgical intervention was decided after removing both kidneys since the patient stopped having orbital angioedema $[1,2]$.

\section{Case}

45-year-old female patient arrives to the medical appointment very distressed and unsatisfied with the appearance of her eyes, "feeling like a little ceiling in both upper eyelids" that causes tiredness, fatigue and the appearance of aging. She was questioned and reported that she suffered from polycystic kidney disease. Both kidneys were removed more than a year ago. As a consequence of poor water management, she presents multiple orbital angioedemas, leaving an excess and laxity of skin in both upper eyelids. She feels permanent irritation, change of texture in the skin of the eyelids and decrease in the lateral visual field. Bio microscopy reveals palpebral laxity that generates significant bilateral blepharochalasis.

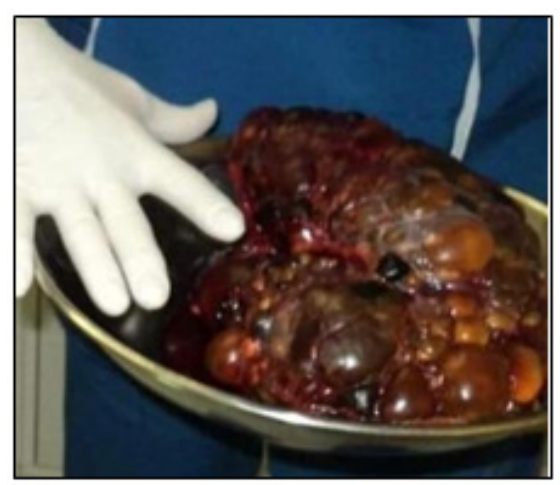

Figure 1: Right Kidney 


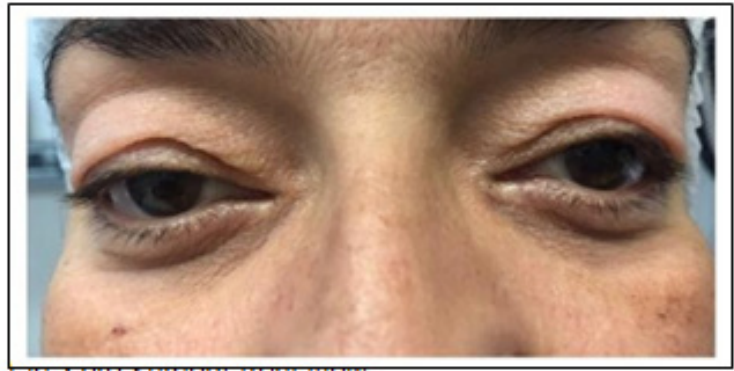

Figure 2: Pre-Surgery Front View

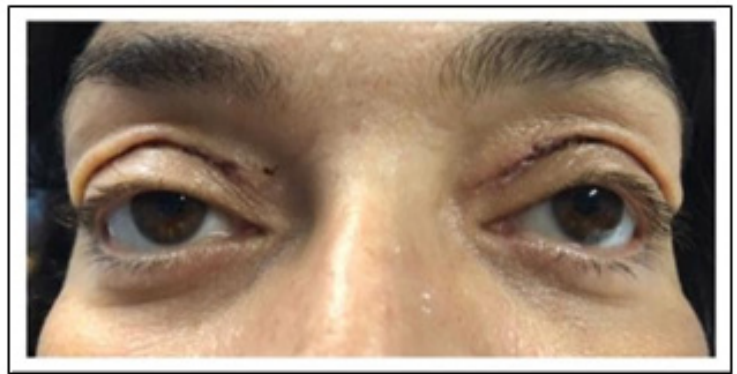

Figure 3: Front View - Post Surgery One Week Later

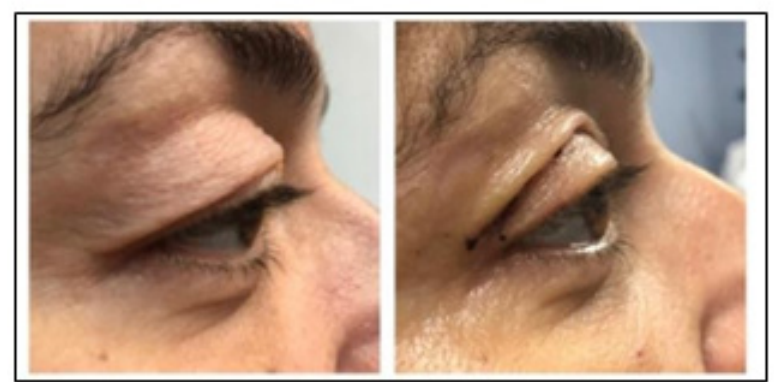

Figure 4: OD - Pre and Post Surgery Side View One Week Later

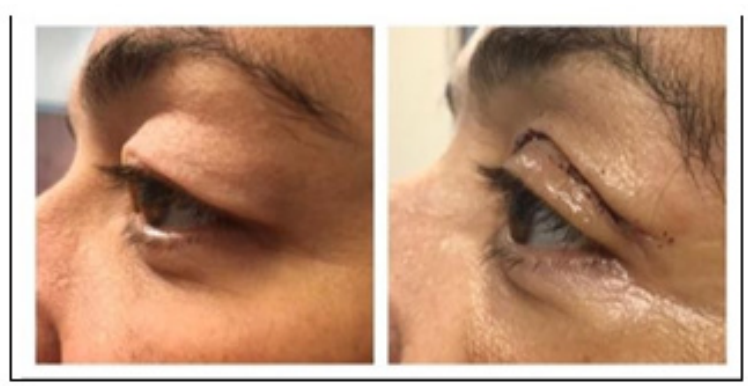

Figure 5: OS - Pre and post-surgery side view one week later

It was decided to perform a superior bilateral blepharoplasty to release excess skin and tighten the orbicularis muscle, as well as to remove the excess fat and remove the upper eyelid pockets.

\section{Conclusion}

She underwent surgery a year ago with a satisfactory emotional and functional result.

\section{Acknowledgement}

None.

\section{Conflict of interests}

Authors declares no conflict of interest.

\section{References}

1. [2016] Kanski's Clinical Ophthalmology: a systematic approach, pag 55, [Ed: 8], Editorial Eisevier España.

2. [2017] Colour Atlas of Ophthalmic surgery, Tyers-Collin, [Ed: 4], Editorial Eisevier España. 